Tohoku J. Exp. Med., 2003, 199, 141-148

\title{
Comparison of DNA Ploidy and Nuclear Morphometric Parameters with the Conventional Prognostic Factors in Transitional Cell Carcinomas
}

\author{
Onder Onguru, Bulent Celasun and Omer Gunhan \\ Department of Pathology, Gulhane Military Medical Academy, School of \\ Medicine, Ankara, Turkey
}

Onguru, O., Celasun, B. and Gunhan, O. Comparison of DNA Ploidy and Nuclear Morphometric Parameters with the Conventional Prognostic Factors in Transitional Cell Carcinomas. Tohoku J. Exp. Med., 2003, 199 (3), 141-148 Carcinomas of the bladder cause important problems of mortality and morbidity despite diagnostic and therapeutic improvements. A variety of grading systems has been developed to reflect the different biologic behavior and malignant potential of this heterogeneous neoplasm. However, these histologic grading systems are subjective and reproducibility is low. In this study, the nuclear morphometric features and DNA ploidy status of 86 cases of transitional cell bladder carcinomas have been studied using image analysis methods with different data selection methods in nucleus suspension to evaluate the relationship of these parameters with the conventional prognostic factors. The relationship between these parameters and likelihood of relapse has also been investigated. In conclusion, the mean nuclear area of the 10 largest nuclei and DNA ploidy status have been shown to be significantly correlated with conventional prognostic factors. Cytomorphometrically, a binary grading system seems more suitable for transitional cell carcinoma of the bladder. For superficial carcinomas, morphometric parameters and DNA ploidy analysis can be helpful in the separation of the patients into prognostically different groups._carcinoma; bladder; morphometry; DNA ploidy; image analysis

(C) 2003 Tohoku University Medical Press

Transitional cell carcinoma (TCC) of urinary bladder is a heterogeneous neoplasm showing a different biological behavior. The majority of the TCCs is early, noninvasive lesions with a tendency to recur and some may progress to invasive tumors (Bane et al. 1996). The stage and the histologic grade of the tumor are important clinicopathologic features for the therapy and prognosis of TCCs (Bane et al. 1996; Stein et al. 1998). However, due to the subjectivity of histological grading systems, the reproducibility of grading is low (Ooms et al. 1983;

Received December 27, 2002; revision accepted for publication March 10, 2003.

Address for reprints: Onder Onguru, GATA Patoloji AD., Etlik 06010 Ankara, Turkey.

e-mail: onguruo@yahoo.com 
Blomjous et al. 1989). For this reason, so far different histological grading systems have been used which assess the morphological characteristics related with the malignancy potential of tumor. The need for an objective and reproducible method for grading has stimulated the investigators for the studies of quantitative analysis by various techniques for TCCs (Ooms et al. 1983; Lipponen et al. 1989; Lipponen and Eskelinen 1990; Lipponen 1993; De Vita et al. 1991; Borland et al. 1993; Tachibana et al. 1994; Fukuzawa et al. 1995; Kruger and Muller 1995; Forte et al. 1997; Ogura et al. 1997; Wojcik et al. 1998; van Velthoven et al. 2000; Ozer et al. 2001).

In this study, using image analysis, the nuclear morphometric features and the DNA ploidy of the transitional cell carcinomas were analyzed with different data selection methods in nucleus suspension and their correlation with the classical prognostic factors was searched. Furthermore, the relation between nuclear morphometric features and the probability of recurrence was investigated.

\section{Materials ANd Methods}

Eighty-six cases were included in this study from 139 patients who undergone transurethral resection of a primary and untreated transitional cell carcinoma of the urinary bladder between 1990 and 1998. Fifty-three cases were excluded because of cauterization artifacts, tissue fixation and processing problems, and inadequate archival material. Each tumor was examined again and histologically graded according to the Ash grading system (Rosai 1996). The cases that had a discrepancy with the original routine histologic grade were assessed with senior pathologists in the department again and finally a prevailing grade was accepted. One tissue block that consisted of the most representative areas of the tumor has been chosen from each specimen for morphometric analysis. Three $50-\mu \mathrm{m}$ sections were cut from paraffin blocks for nuclear extraction. Five- $\mu \mathrm{m}$ sections were cut from paraffin blocks before and after the thick sections, stained with hematoxylin and eosin $(\mathrm{H} \&$ E) and examined to confirm the presence of representative tumor cells. Extraction of nuclei was accomplished by the method of Hedley et al. (1983) with slight modification. Briefly, tissue sections were deparaffinized and rehydrated in xylene and in a series of decreasing concentrations of ethanol to water. The tissue was incubated for 45 minutes at $37^{\circ} \mathrm{C}$ in $1 \mathrm{ml}$. of $0.5 \%$ pepsin $(\mathrm{pH}=1.5)$. After pepsin digestion, samples were washed with phosphate buffered saline solution (PBS). The sample concentration was adjusted with PBS and cytocentrifuge preparations have been made. Then, the slides were stained with new fuchsin, as described by Böcking et al. (1995).

The equipment used for morphometric analysis included a three-chip CCD color video camera (Sony, Tokyo) attached to a light microscope (Zeiss Axioskop, Gottingen, Germany) and an IBM compatible computer with Pentium 233 MMx processor, 128 RAM, Matrox Meteor frame grabber (Matrox Imaging, Dorval, Quebec, Canada) and 21 inch video monitor (Philips, Chungli, Taiwan). The images of Feulgen-stained nuclei on slides transferred with 63x-oil immersion objective have been analyzed with Autocyte ${ }^{\circledR}$ QUIC DNA 1995-1998 program (Burlington, NC, USA) that has a capacity to measure approximately 100 morphometric parameters. The system permitted measurements of total nuclear optical density, which can then be expressed in terms of ploidy value. Briefly, the analysis procedure was as follows: initialize application, select fields of interest, process nuclei, and record the measurement results. Each slide was independently calibrated. The instrument was calibrated with rat hepatocyte nuclei for external control. For each case, at least 200 tumor cells (range, 215 -545) were measured. Overlapping or fragmented nuclei were not measured. 
Lymphocytes served as internal controls to define the diploid peak. At least 30 lymphocytes (range, 31-45) were analyzed. A DNA histogram was generated for each case and classified by software into one of four Auer groups (Auer et al. 1980). Group 1 included histograms with a prominent, single DNA peak at $2 \mathrm{c}$ (diploid) region. Group 2 included histograms with a dominant DNA peak at the 2c region and some cells $(>10 \%)$ with $>5 \mathrm{c}$ DNA content. Group 3 included histograms with an aneuploid peak or peaks and variable number of cells $>5$ c. Group 4 included histogram with multiple cell lines and no identifiable dominant clone. DNA index (DI) for each case and measurements of nuclear areas of tumor cells have also been generated by Autocyte $^{\circledR}$ program. We calculated the mean nuclear area of the all tumor cells (NA) measured and mean nuclear area of the 10 largest nuclei (NA10) for each case. Two pathologists together evaluated the results of morphometric measurements on the stored images of each case.

Statistical analysis of the data was carried out on an IBM compatible computer using SPSS (Scientific Package for Social Sciences) 7.5 program. Statistical difference was evaluated by non-parametric tests, since most variables in each group were not distributed normally. Kruskal-Wallis analysis was used at first to assess whether statistical difference was present between four histological grades or not. Then, Mann-Whitney's U-test for NA, NA10 and DI were done for the statistical differences between grade I and II, grade II and III, grade III and IV, muscle invasive and non-invasive groups. A probability value $(p)$ of less than 0.05 was considered significant. Besides, the relation between DI and nuclear area was analyzed by regression test.

\section{RESULTS}

The distribution of cases according to histopathologic grade and stage at the time of diagnosis is shown in Table 1 . Pathological examination revealed that 59 cases were superficial tumors (stage $\mathrm{Ta}$ and $\mathrm{T} 1$ ) and the remaining 27 were advanced lesions (stage $\mathrm{T} 2$ to T4). Eleven cases were classed as grade I, 42 as grade II, 23 as grade III, and 10 as grade IV.

The mean \pm S.D values of nuclear areas in different histologic grade groups for two different methods are shown in Table 2.

The differences between four histologic grades were significant for both methods $(p=$ $0.0001)$. The difference between grade II and grade III for NA10 $(p=0.0001)$ was significantly greater than the difference for NA $(p=0.027)$. However, the differences between grade I and II, and between grade III and IV were not statis-

TABLE 1. The distribution of tumor grade and stage

\begin{tabular}{crrrr}
\hline & \multicolumn{3}{c}{ Stage } & Total \\
\hline Histological grade & $\mathrm{T}_{\mathrm{a}}$ & $\mathrm{T}_{1}$ & $\mathrm{~T}_{2-3}$ & \\
\hline I & 7 & 4 & - & 11 \\
II & 11 & 29 & 2 & 42 \\
III & - & 7 & 16 & 23 \\
IV & - & 1 & 9 & 10 \\
Total & 18 & 41 & 27 & 86 \\
\hline
\end{tabular}

TABLE 2. The mean \pm S.D. values of nuclear area (NA) and the 10 largest nuclear area (NA10) in different histological grades

\begin{tabular}{|c|c|c|}
\hline & NA & NA10 \\
\hline \multicolumn{3}{|c|}{ Histological grade } \\
\hline $\mathrm{I}(n=11)$ & $71.8 \pm 19.8$ & $118.1 \pm 15.4$ \\
\hline II $(n=42)$ & $83.6 \pm 26.2$ & $149.2 \pm 38.1$ \\
\hline II $(n=23)$ & $95.9 \pm 27.9$ & $200.9 \pm 52.7$ \\
\hline IV $(n=10)$ & $116.1 \pm 34.1$ & $242.3 \pm 70.9$ \\
\hline
\end{tabular}

TABLE 3. The differences between histologic grades for nuclear area (NA) and the 10 largest nuclear area (NA10)

\begin{tabular}{cccc}
\hline & 1 and 2 & 2 and 3 & 3 and 4 \\
\hline NA & $p=0.059$ & $p=0.027^{*}$ & $p=0.180$ \\
NA10 & $p=0.051$ & $p=0.0001^{*}$ & $p=0.123$ \\
\hline
\end{tabular}

*Statistically significant difference $(p<0.05)$. 
tically significant for either NA10 or NA (Table 3).

All of the gradeI cases were diploid. Grade II and grade III cases were heterogeneous. Of the grade II cases, 31 were diploid, 11 were aneuploid. Of the grade III cases, 7 were diploid, 16 were aneuploid. All of the grade IV cases were aneuploid (Table 4).

The statistical difference for DNA indices between grade II and III was significant $(p=$ 0.0001)(Fig. 1). However, the differences for DNA indices between grade I and II, and

Table 4. DNA ploidy status of cases for histological grades

\begin{tabular}{ccc}
\hline & \multicolumn{2}{c}{ DNAploidy (numberofcases) } \\
\cline { 2 - 3 } & Diploid & Aneuploid \\
\hline Histological grade & & \\
I & 11 & - \\
II & 31 & 11 \\
III & 7 & 16 \\
IV & - & 10 \\
Total & 49 & 37 \\
\hline
\end{tabular}

between grade III and IV were not significant ( $p=0.056, p=0.923$, respectively). On the other hand, the relation between NA10 and DNA index was significantly better than the relation between NA and DNA index $(r=0.650, r=0$. 486, respectively).

To evaluate the association of invasion with DNA ploidy and nuclear area, the cases were divided into two groups as muscle invasive and muscle non-invasive. The differences for NA10 and DNA index between muscle invasive and non-invasive groups were significant $(p=$ 0.0001 for both). The difference for NA was not significant $(p=0.04)$. Twenty-two $(81 \%)$ of the 27 muscle invasive cases were aneuploid. However, 15 (25\%) of 59 muscle non-invasive cases were aneuploid.

Of all, 11 cases had recurrences. Six of the 11 recurred cases were superficial tumors with histological grade II. The other 5 cases with recurrences had muscle invasion and 3 of them were grade III and one grade IV. All of the cases with recurrences were aneuploid tumors.

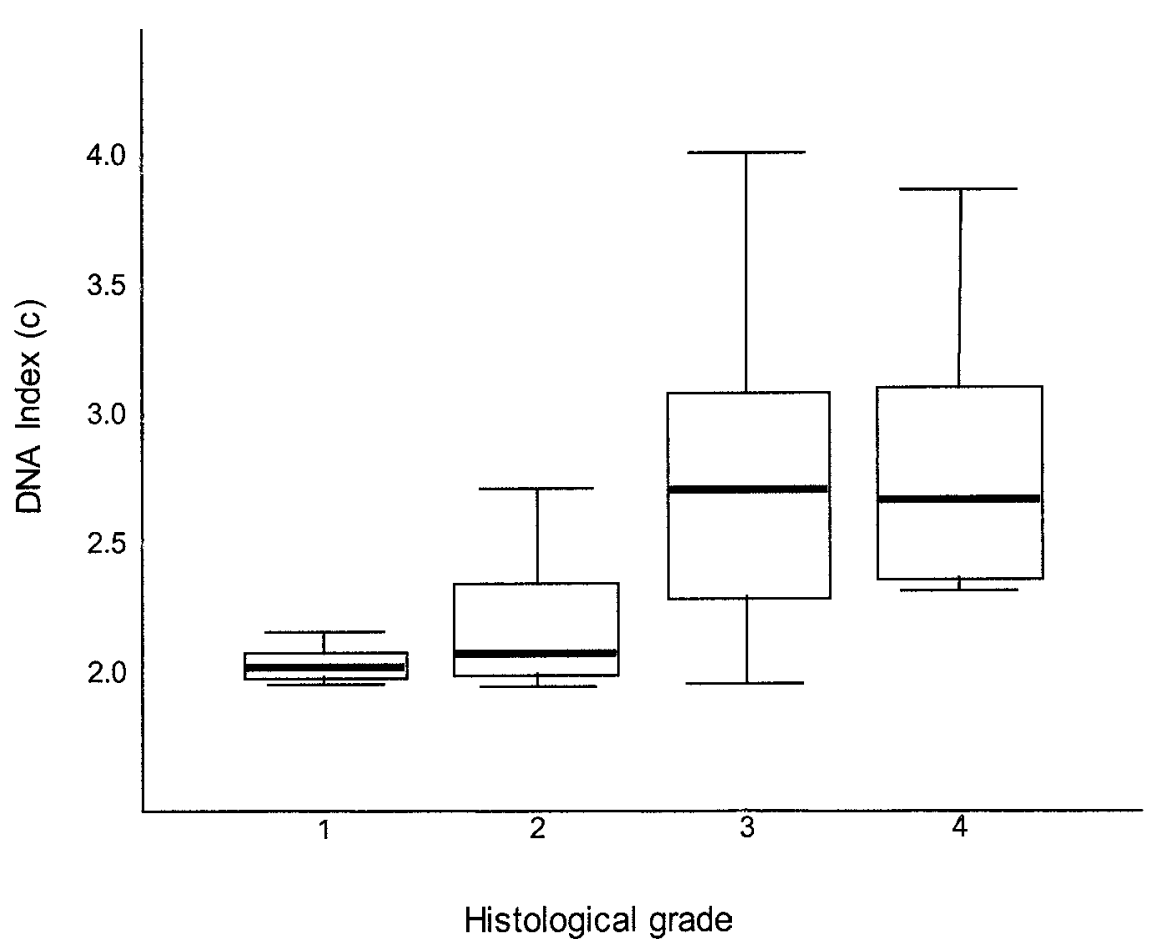

Fig. 1. The DNA indices in tumors of different histological grades. 


\section{DISCUSSION}

Our fundamental knowledge that is the correlation of tumor growth with the increased mitotic activity, DNA aneuploidy and pleomorphism is also valid for the transitional cell carcinomas (TCCs). Many studies have been performed so far in order to prove this fact by different kinds of morphometric measurements (Ooms et al. 1983; Lipponen et al. 1989; Lipponen and Eskelinen 1990; Borland et al. 1993; Lipponen 1993; Tachibana et al. 1994; Ogura et al. 1997; Wojcik et al. 1998; van Velthoven et al. 2000; Ozer et al. 2001). Due to the developing technology, imaging and software advances have contributed to the refinement of our current morphometric system. On the other hand, the new techniques made it possible to study the quantitative morphologic assessment of nuclei extracted from paraffin blocks (Hendricks et al. 1993). Lipponen et al. (1990) measured the nuclear area of at least 50 cells (50 -84), that were selected on the sections stained with $\mathrm{H} \& \mathrm{E}$ from the most atypical field of carcinoma. They found that the nuclear areas of the tumor cells in TCCs had changed with the histological grade and the standard deviation of NA and histological grade exhibited a clearly significant relation. On the other hand, Blomjous et al. $(1989,1990)$ measured the nuclear area of the biggest 10 cells through the H\&E stained sections on the most atypical areas. A morphometric analysis system with a projection microscope equipped with a 100x oil immersion objective, projecting at a graphic tablet was used in their study. Due to the selection of big cells and the most atypical areas, the subjectivity is being preferred in a conscious manner in their study. In our study, the two different data selection methods were applied involving the mean nuclear area of the biggest 10 cells (NA10) and the mean nuclear area (NA) of the all cells that are measured in each case. It was found that the nuclear area increased with histologic grade for both methods. It was also observed that a statistically significant difference was present between grade II and grade III tumors. The statistical difference was more evident for NA10 measurements $(p=0.001)$. Either from the aspect of NA or NA10, no statistically significant difference was observed between grade III and grade IV, or between grade I and II. The measurement of NA10 in this study demonstrated the mean nuclear area of the biggest 10 cells among the all cells measured at the nucleus suspension for each case. Thus, the subjectivity of selecting nuclei was minimalized by using the nucleus suspension method. In the previous studies, the morphometric measurements were performed in $\mathrm{H} \& \mathrm{E}$ stained slides. Especially the morphometric distinction in the measurements of NA10 became more evident through the nucleus suspension method applied in this study. Therefore, it was considered to be more objective and reproducible method when compared to the other methods applied in order to measure the biggest nucleus within the most atypical areas on the $\mathrm{H} \& \mathrm{E}$ sections.

The TCCs were classified according to the morphometric nuclear area measurements using double or triple grading scales (Lipponen et al. 1989; Lipponen and Eskelinen 1990; Sowter et al. 1991). While the adequacy ratio was observed as nearly $92 \%$ at the triple grading system, this ratio was $96 \%$ at the double grading system (Lipponen et al. 1989). Although the results of NA and NA10 results complied with each other at a great scale in this study, especially statistically significant difference existed between grade II and grade III tumors in regard with NA10 measurements (Table 3). This finding also supported that the TCCs could be split cytomorphometrically into two groups through the measurements of NA10. It has been pointed out that such a simple morphometric classification could also lead to an approach of a more effective therapy clinically (Lipponen et al. 1989; Blomjous et al. 1990). The DNA indices of the cases compared with the his- 
tological grades have also supported the morphometric double grading system. In many histological grading systems, the enlargement of nuclear area and pleomorphism had constituted the major criteria for the grading of progressed tumors. To our knowledge, a study that had been performed according to the Ash histological grading system was not present in the literature. However, this study revealed that the Ash grading system had a good compliance with the morphometric grading and the grade I and II tumors generally consisted of cells having a small nuclei and mostly in diploid nature whereas the grade III and IV tumors contained cells having a rather large nuclei and mostly in aneuploid nature. On the other hand, morphometric grading of TCCs into two groups could also support the WHO-ISUP histologic grading of TCCs as low-grade and high-grade urothelial neoplasms (Epstein et al. 1998).

The cytogenetic and flow cytometric studies have shown that the nuclear enlargement in the progressed neoplasms took place together with the abnormal amount of nuclear DNA (Helander et al. 1985). When the relation of DNA index with the nuclear area was analyzed, it was seen that NA10 was better correlated $(r=0.650)$ with the DNA index than NA $(r=$ 0.486). This finding have demonstrated that it would be more beneficial to use NA10 instead of $\mathrm{NA}$ in regard with the prospective evaluation of TCC cases.

In this study, it was determined that the TCCs with invasion into the muscular layer had a rather large nucleus when compared with the superficial TCCs (TA and T1). The correlation of NA10 with the invasion was quite significant $(p=0.0001)$ and such a correlation was rather low $(p=0.04)$ in NA. A significant correlation $(p=0.00001)$ also existed between DNA index and invasion and so forth it was seen that many of the cases with muscle invasion were aneuploid. According to this finding, the DNA ploidy of TCCs seemed to be shifting to the aneuploid direction while the invasion getting deeper.

The correlation of some nuclear morphometric parameters with prognosis of TCCs was also studied (Blomjous et al. 1990; Lipponen and Eskelinen 1990; Borland et al. 1993; Ozer et al. 2001). It was demonstrated that the standard deviation of nuclear area was the most important morphometric parameter followed by nuclear area and NA10, the latter two being about equally effective (Lipponen and Eskelinen 1990). On the other hand, Borland et al. (1993) measured the nuclear area of 150 tumor cells in the TCCs with deep muscular layer invasion. This study indicated a significant correlation between nuclear area and prognosis. Depending on this finding it was pointed out that the nuclear morphometry would be beneficial in the selection of patients that should receive adjuvant chemotherapy following a cystectomy procedure.

It was also reported that the cytomorphometric features of the primary tumor were important factors in the determination of tumor recurrence (Blomjous et al. 1990; Lipponen and Eskelinen 1990; Borland et al. 1993; van Velthoven et al. 2000). Van Velthoven et al. (2000) studied nuclear DNA content, nuclear morphometry and chromatin patterns in a large series of patients with superficial TCC by computer assisted image microscopy applied to Feulgen stained nuclei in order to characterize the risk of recurrence and/or progression. In their study, they found a cutoff value with discriminant analysis of cytometric variables for distinguishing between low and high risks of recurrence. On the other hand, Ozer et al. (2001) performed nuclear morphometry by a computer-assisted image analyzer system on $\mathrm{H}$ \& E-stained histologic sections and evaluated nuclear area, perimeter, major and minor diameter, and form factor in superficial (pTa and pT1) bladder cancer. No corelation was found between morphometric variables and tumor progression and recurrence in their study (Ozer et al. 2001). Eleven of 86 cases in our study 
showed a recurrence and all of these cases were aneuploid tumors. The invasion degree and recurrence rate of aneuploid TCCs seemed to be higher than the diploid TCCs. Therefore, aneuploidy thought to be especially important for the superficial TCCs. Among the total 59 cases of superficial TCCs in this study, 15 were aneuploid. If we take into the consideration that 6 cases of 15 aneuploid superficial TCCs have shown a recurrence, it can be considered that aneuploidy in superficial TCCs may present a risk factor in regard with the progression and recurrence and they should be more closely pursued than the diploid ones.

\section{References}

Auer, G., Caspersson, T. \& Wallgreen, A. (1980) DNA content and survival in mammary carcinoma. Analyt. Quant. Cytol., 3, 161-165.

Bane, B.L., Rao, J.Y. \& Hemstreet, G.P. (1996) Pathology and staging of bladder cancer. Semin. Oncol., 23, 546-570.

Blomjous, E.C.M., Smeulders, A.W.M., Baak, J.P.A., Vos, W., Van Galen, C.M. \& Meijer, C.J.L. (1989) A comparative study in morphometric grading of transitional cell carcinoma of the urinary bladder. Anal. Quant. Cytol. Histol., 11, 426-432.

Blomjous, E.C.M., Vos, W., Schipper, N.W., Uyterlinde, A.M., Baak, J.P.A., Voogt, H.J. \& Meijer, C.J.L. (1990) The Prognostic significance of selective nuclear morphometry in urinary bladder carcinoma. Hum. Pathol., 21, 409-413.

Borland, R.N., Partin, A.W., Epstein, J.I. \& Brendler, C.B. (1993) The Use of nuclear morhometry in predicting recurrence of transitional cell carcinoma. J. Urol., 149, 272-275.

Böcking, A., Giroud, F. \& Reith, A. (1995) Consensus report of the European Society for Analytical Cellular Pathology Task Force on standardization of diagnostic DNA image cytometry. Anal. Quant. Cytol. Histol., 17, 17.

De Vita, R., Forte, D., Maggi, F., Eleuteri, P. \& Silverio, F. (1991) Cellular DNA content and proliferative activity evaluated by flow cytometry versus histopathological and staging classifications in human bladder tumors. Eur. Urol., 19, 65-73.
Epstein, J.L., Amin, M.B., Reuter, V.R. \& Mostofi, F.K. (1998) The World Health Organisation / International Society of Urological Pathology consensus classification of urothelial (transitional cell) neoplasms of the urinary bladder. Am. J. Surg. Pathol., 22, 14351448.

Forte, J.D., Croker, B.C. \& Hendricks, J.B. (1997) Comparison of histologic and cytologic specimens of urothelial carcinoma with image analysis. Anal. Quant. Cytol. Histol., 19, 158166.

Fukuzawa, S., Hashimura, T., Sasaki, M., Yamabe, H. \& Yoshida, O. (1995) Nuclear morhometry for improved prediction of the prognosis of human bladder carcinoma. Cancer, 76, 1790-1796.

Hedley, D.W., Friedlander, M.L., Taylor, I.W., Rugg, C.A. \& Musgrove, E.A. (1983) Method for Analysis of Cellular DNA Content of Paraffin-embedded Pathological Material Using Flow Cytometry. J. Histochem. Cytochem., 31, 1333-1335.

Helander, K., Kirkhus, B., Iversen, O.H., Johansson, S.L., Nilsson, S., Vaage, S. \& Fjordvang, H. (1985) Studies on urinary bladder carcinoma by morphometry, flow cytometry, and light microscopic malignancy grading with special reference to grade II tumours. Virchows Arch. (Pathol. Anat.), 408, 117-126.

Hendricks, J.B., Wilkinson, E.J., Pharis, P.J., Sapi, Z. \& Braylan, R.C. (1993) Quantitative morphologic assessment of nuclei extracted from paraffin for DNA flow cytometry. Mod. Pathol., 6, 565-569.

Kruger, S. \& Muller, H. (1995) Correlation of morphometry, nucleolar organizer regions, proliferating cell nuclear antigen and Ki 67 antigen expression with grading and staging in urinary bladder carcinomas. Br. J. Urol., 75, 480-484.

Lipponen, P., Simpanen, H., Pesonen, E., Eskelinen, M., Sotarauta, M. \& Collan, Y. (1989) Potential of morphometry in grading transitional cell carcinoma of the bladder. Path. Res. Pract., 185, 617-620.

Lipponen, P. \& Eskelinen, M. (1990) Nuclear morphometry in grading transitional cell bladder cancer compared with subjective histological grading. Anticancer Res., 10, 1725-1730.

Lipponen, P. K., Collan, Y., Eskelinen, M.J., Pesonen, E. \& Sotarauta, M. (1990) Morphometry in 
human transitional cell bladder cancer (nuclear area and standard deviation of nuclear area-relation to tumor grade (WHO) and prognosis). Eur. Urol., 17, 155-159.

Lipponen, P.K. (1993) Stereologically measured nuclear volume in comparison to twodimensional nuclear morphometry, mitotic index and flow cytometry in predicting disease outcome in bladder cancer. Anticancer Res., 13, 529-532.

Ogura, K., Fukuzawa, S., Habuchi, T., Ogawa, O. \& Yoshida, O. (1997) Correlation of nuclear morphometry and immunostaining for p53 and proliferating cell nuclear antigen in transitional cell carcinoma of the bladder. Int. J. Urol., 4, 561-566.

Ooms, E.C.M., Anderson, W.A.D., Alons, C.L., Boon, M.E. \& Veldhuizen, R.W. (1983) Analysis of the performance of pathologists in the grading of bladder tumors. Hum. Pathol., 14, 140-143.

Ozer, E., Yorukoglu, K., Mungan, M.U., Ozkal, S., Demirel, D., Sagol, O. \& Kirkali, Z. (2001) Prognostic significance of nuclear morphometry in superficial bladder cancer. Anal. Quant. Cytol. Histol., 23, 251-256.

Rosai, J. (1996) Bladder and male urethra. In: Ackerman's Surgical Pathology, 8th ed., Mosby-Year Book, Inc., St. Louis, Missouri, pp. 1197-1201.
Sowter, C., Slavin, G., Sowter, G. \& Hendry, W. (1991) Morphometry of bladder carcinoma: Morphometry and grading complement each other. Anal. Cell. Pathol., 3, 1-9.

Stein, J.P., Grossfeld, G.D., Ginsberg, D.A., Esrig, D., Freeman, J.A., Figueroa, A.J., Skinner, D.G. \& Cote, R.J. (1998) Prognostic markers in bladder cancer: A contemporary review of the literature. J. Urol., 160, 645-659.

Tachibana, M., Degucci, N., Jitsukawa, S., Baba, S., Hata, M. \& Tazaki, H. (1994) Quantification of cell kinetic characteristics using flow cytometric measurements of DNA and bromodeoxyuridine for bladder cancer. $J$. Urol., 145, 963-967.

Van Velthoven, R., Petein, M., Oosterlinck, W., De Wilde, T., Mattelaer, J., Hardeman, M., Kiss, R. \& Decaestecker, C. (2000) Identification by quantitative chromatin pattern analysis of patients at risk for recurrence of superficial transitional bladder carcinoma. J. Urol., 164, 2134-2137.

Wojcik, E.M., Miller, M.C., O'Dowd, G.J. \& Robert, W.V. (1998) Value of computer-assisted quantitative nuclear grading in differentiation of normal urothelial cells from low and high grade transitional cell carcinoma. Anal. Quant. Cytol. Histol., 20, 69-75. 